\title{
VII
}

\section{A DESCOLONIZAÇÃO E A DECOLONIALIDADE COMO POSSIBILIDADES NA CONSTRUÇÃO DO ENSINO DE HISTÓRIA NA ESCOLA BÁSICA*}

\author{
Veruschka de Sales Azevedo ${ }^{1}$
}

O debate sobre o processo de descolonização do saber tem ganhado fôlego, sobretudo no limiar do século XXI. Os movimentos por direitos sociais reivindicam a visibilidade e os espaços de saber e poder. Nessa perspectiva emergem alguns debates centrais voltados para a valorização e resgate dos conhecimentos e da história das populações subalternizadas historicamente, no caso do Brasil: a população negra e a indígena.

O impacto dos questionamentos no campo do conhecimento (MALDONADO, 2020; GOMES, 2012; WALSH, 2009: MUNANGA, 2013) aponta a necessidade de repensarmos os currículos escolares. O projeto de colonização cultural permanece como um fenômeno de longa duração.

A racialização das vidas negras e indígenas contribuíram ao longo da história do Brasil para que tais sujeitos fossem destituídos do estatuto de corpos pensantes e fazedores de cultura. Nesta trajetória, raça emerge como um conceito central para que a aparente contradição entre a universalidade da razão e o ciclo de morte e destruição do colonialismo e da escravidão possam operar simultaneamente como fundamentos irremovíveis da sociedade contemporânea. (ALMEIDA, 2019 p. 28). Esse processo ocorre desde a conquista das terras brasileiras no século XVI, e, mais precisamente, no século XIX quando assistimos a atualização dos conceitos de bárbaros e civilização.

A reestruturação do capitalismo no século XIX, na fase da $2^{a}$ Revolução tecnocientífica, reelaborou as narrativas científicas e eurocêntricas e tal processo foi responsável por um amplo domínio econômico, material e cultural da América, Ásia e África. A base científica difundiu, naturalizou e universalizou a cultura, na qual o modelo civilizatório, os modos de vida, a inteligência, o ser humano devia ser branco, europeu e masculino:

*DOI- 10.29388/978-65-86678-50-5-0-f.145-170

${ }^{1}$ Doutora em História Social (PUC /SP). Professora de História da Rede Básica de Educação do estado de São Paulo e membro do GT de Ensino de História da ANPUH/SP. 
O espírito positivista surgido no século XIX transformou as indagações sobre as diferenças humanas em indagações científicas, de tal sorte que de objeto filosófico, o homem passou a ser objeto científico. A biologia e a física serviram como modelos explicativos da diversidade humana: nasce a ideia de que características biológicas- determinismo biológico- ou condições climáticas e/ou ambientais-determinismo geográfico -seriam capazes de explicar as diferenças morais, psicológicas e intelectuais entre as diferenças de raças. Desse modo, a pele não branca e o clima tropical favoreciam o surgimento de comportamentos imorais, lascivos e violentos, além de indicarem pouca inteligência. Por essa razão Arthur Gobineau recomendou evitar a "mistura de raças", pois o mestiço tendia a ser mais "degenerado". Esse tipo de pensamento, identificado como racismo científico obteve enorme repercussão e prestígio nos meios acadêmicos e políticos do século XIX, como demonstram, além das de Arthur Gobineau, as obras de Cesare Lombroso, Enrico Ferri e, no Brasil, Silvio Romero e Raimundo Nina Rodrigues" (ALMEIDA, 2019, p. 29).

O educador e pesquisador das relações étnico-raciais Luiz Rufino, em um recente estudo sobre o racismo e os saberes ancestrais da população negra no Brasil, entende que, "A raça é a invenção que precede a noção de humanidade no curso da empreitada ocidental, o estatuto de humanidade empregado ao longo do processo civilizatório colonial europeu no mundo é fundamentado na destruição dos seres não brancos”. (RUFINO, 2019, p. 11).

Analisar as ausências da história da população afro-brasileira e dos povos originários nos espaços de saber, sobretudo no contexto da sociedade do século XXI, é chamar um firme debate sobre a perspectiva da importância das vidas negras e indígenas na história do Brasil e nos currículos e espaços escolares. Ao enfrentamento à padronização e hegemonia eurocêntrica do Currículo Paulista, na área de História, chamaremos de descolonização do currículo.

Assim, a descolonização deve emergir não somente como um mero conceito, mas também como uma prática permanente de transformação social da vida comum, é, logo, uma ação rebelde, inconformada, em suma, um ato revolucionário. Por mais contundente que venha a ser o processo de libertação, é também um ato de ternura, amor e responsabilidade com a vida. A colonização acarreta o destroçamento dos seres subordinados a esse regime, os colonizados, mas também a bestialização do opressor, o colonizador. Sobre a colonização não se ergue civilização, mas sim barbárie[...]. (RUFINO, 2019, p. 11). 
A valorização dos saberes negros e dos povos originários na história do Brasil até um passado recente era considerado caso de polícia, seguindo à risca a perspectiva apontada pelo neocolonialismo da era dos impérios, qual seja, o privilégio branco, masculino e europeu. Estudando o processo de modernização empreendido nos núcleos urbanos no século XIX, na Primeira República, notamos a materialização do ideário neocolonial: a desumanização dos corpos negros no cotidiano das cidades, a brutalidade e perpetuação das práticas de inferiorização se tornaram a norma presente na vida cotidiana, uma espécie de banalidade do mal que segue até os dias atuais, ancorada na teoria da democracia racial, construída para acomodar corpos e mentes.

As instituições educacionais reproduziam a lógica da segregação e normatização dos valores europeus, ou seja, a reprodução do currículo eurocêntrico. Estabeleceram, por meio das instituições propagadoras da cultura como a escola e seus respectivos currículos, práticas de exclusão e ausências consentidas e naturalizadas pela população em quase toda sua maioria. A construção de todo esse processo foi acompanhada de muita luta e reivindicação dos principais sujeitos excluídos, negros e indígenas. No caso deste texto, destacaremos a luta da cultura negra questionando o poder público e a história e lutando por direitos sociais e visibilidade, a partir da reflexão de uma produção musical da capoeira e da escrita crítica de Carolina Maria de Jesus.

A luta do Movimento Negro Unificado ao se reorganizar nos anos de 1978 trouxe em sua agenda a questão da necessidade de inclusão de negros e negras nos espaços de conhecimento formal e contribuiu muito para o cenário em que vivemos nos dias atuais de crescimento de um público negro, indígenas e segmentos populares dentro dos estabelecimentos de ensino. Porém, a luta não se reduz à educação formal, visa também promover um processo social, cultural, pedagógico e político dos negros e negras e reeduca os outros segmentos étnico-raciais (GOMES, 2018, p. 130).

O processo de integração do conjunto dos brasileiros no sistema de ensino foi anunciado enquanto política de Estado somente em fins do século XX, com a Constituição Federal de 1988 e a Lei de Diretrizes e Bases de 1996.

A recuperação desse aspecto ajuda a entender a trajetória das ausências de grupos oriundos das camadas sociais populares no sistema de ensino, por sua vez, a falta de temas e eixos formativos que expressassem uma relação direta com a vida dos sujeitos envolvidos no processo de ensino, consolidando a cultura racista que permeou todo o sistema de ensino formal no país. Essa prática veio a ser questionada com mais rigor quando da implementação da Lei 
10.639/03 que alterou a lei de diretrizes e bases, obrigando o estudo da cultura e história dos africanos e afro-brasileiros nos currículos de escolas públicas e privadas em todo o país.

Outra legislação importante é a Lei 11.645/08 que obriga a inclusão da história de negros e indígenas nos currículos escolares. Ambas se constituíram dentro de outro cenário político, marcado pela ascensão dos governos populares que operaram para a ampliação das políticas reparatórias.

Há a chegada de um público novo no sistema de ensino, tanto na educação básica quanto no nível superior, sobretudo, grupos subalternizados historicamente, como as camadas populares periféricas e, portanto, grande parte da população negra. Os alunos indígenas e segmentos que começaram a trazer para a escola e para a academia um conjunto de temas e lutas por direitos e identidades, todos provenientes de processos desenvolvidos no desdobramento dos parcos avanços das lutas por identidade, inclusão e respeito, já denunciados por Maria Beatriz Nascimento (2018), Lélia Gonzalez (2010), Abdias Nascimentos (2016), entre outros.

Os questionamentos dos grupos sociais que estão hoje no interior dos sistemas de ensino recaem radicalmente sobre a forma pela qual os currículos são construídos. "Os currículos escolares que temos atualmente são reflexos da história do país. Fundamentalmente baseiam-se na questão da dominação. Em todas as sociedades ocidentais que conhecemos, a educação é monopólio do Estado" (MUNANGA, 2013, p.28).

A necessidade de ampliação do debate sobre a descolonização curricular e de mentes se faz urgente, na história, no mundo do trabalho e nas relações do poder e do saber.

Acompanhar a análise desse processo nas escolas, sobretudo no ensino de História, é pensar a escola e o processo de descolonização curricular em São Paulo. Como está organizado e estruturado o currículo do Estado de São Paulo, no chamado "São Paulo Faz Escola", ou seja, a nova versão, implementado em 2019? Como este currículo trata o debate decolonial?²

\footnotetext{
${ }^{2}$ Notas:

O Currículo do Estado de São Paulo implantado em 2008, sob o nome do projeto São Paulo Faz. Escola, e atualizado em 2011 na área de ciências humanas e suas tecnologias, trazia o nome de Currículo do Estado de São Paulo. Os autores que assinavam pela área de História, podemos ler o material apresentado a professores e alunos, os nomes de Paulo Miceli, Diego López Silva, Glaydson José da Silva, Mônica Lungov Bugelli e Raquel dos Santos Funari. A implantação foi acompanhada de mobilizações e críticas à forma no qual foi elaborado e implementado, nos fazendo entender a crescente correlação de forças entre o professorado e o governo. Contudo, o Currículo do Estado de São Paulo trazia algumas referências bibliográficas, nas quais era possível visualizar indicações mínimas referências as temáticas decoloniais, alguma menção a história da
} 
A apresentação do currículo deixa nítida a preocupação com a questão da BNCC, ou seja, a reestruturação aponta para o que podemos chamar de " 0 mais do mesmo", visto que desde o ano de 2008 a reelaboração do material e até mesmo da prática docente vem sendo objeto de fundações e parcerias realizadas pelo Estado.

Ocorre que esse processo vem se agravando e, em tempos de ultraliberalismo, verificamos um reducionismo até mesmo do campo dos eixos temáticos do ensino de História e uma crescente relação com os valores e toda a engrenagem de interesses que norteiam a BNCC.

O reconhecimento do multiculturalismo funcional na redação da apresentação do Currículo Paulista do segundo semestre de 2019, configura-se uma retórica oca, que anuncia o reconhecimento de todos, todas e todes, mas não tem nenhum compromisso em efetivar uma educação voltada para a emancipação dos valores democráticos e humanistas. Vejamos:

Promover a equidade supõe também dar respostas adequadas e com respeito ao público atendido nas modalidades da Educação Especial, Educação de Jovens e Adultos, Educação do Campo, Educação Escolar Indígena e Educação Escolar Quilombola, segundo as necessidades locais. (Currículo Paulista, 2019, p. 27).

Embora a redação da apresentação do currículo Paulista, na área de ciências humanas e a interpretação pareçam ter um caráter mais geral, ela incide sobre o currículo de História, pois anuncia enfoques caros ao processo de revisão curricular, que leva em consideração as temáticas étnico-raciais, mas não os cumpre. Posto que o regime de implantação do atual currículo nas escolas está focado nas habilidades e competências que os professores devem seguir de acordo com o que vem estipulado na apostila, isto submete o desenvolver das aulas ao prescrito pelos órgãos estatais.

\footnotetext{
África. O que na prática não era contemplado, devido a própria lógica do projeto, ampliar e melhorar o resultado dos alunos em testes externos, leia-se: SARESP e exames externos.

Sabemos que os documentos educacionais espelham o contexto sociopolítico que vivemos e neste sentido, o atual currículo Paulista implantado em 2019 no governo Dória, conseguiu se fazer ainda mais distante das referências decoloniais, e cada vez mais em diálogo com as fundações e setor privado. Podemos dizer que o atual currículo Paulista, está muito alinhado ao projeto da Base Nacional Comum Curricular, porém tanto o Currículo do estado de São Paulo de 2008 como o Currículo Paulista de 2019, oferecem ao aluno o material didático em forma de apostilado com o nome de São Paulo faz escola.

Na prática é o mesmo Projeto, a Secretaria da Educação do Estado de São Paulo (SEESP) criou o Programa São Paulo Faz Escola (SPFE), que foi implementado em 2008, e ainda hoje (2019), está em vigor na rede estadual de ensino paulista. O nome dos materiais permanece e na essência verificamos o aprofundamento do projeto no controle das práticas pedagógicas do professorado.
} 
$\mathrm{Na}$ parte dedicada à área de História do Ensino Fundamental, o Currículo Paulista traz o conceito de "atitude historiadora", apontando uma perspectiva de autonomia e de atitude crítica da atuação do professor de História. A leitura rápida do material mobiliza uma expectativa de democracia e participação dos professores de História e do processo ensino aprendizagem:

O termo "atitude historiadora", no Currículo Paulista, refere-se ao movimento que professores e estudantes devem realizar para se posicionarem como sujeitos frente ao processo de ensino e aprendizagem, fazendo uso da comparação, contextualização e interpretação das fontes, refletindo historicamente sobre a sociedade na qual vivem, analisando e propondo soluções (Currículo Paulista, 2019, p. 455).

O estudo da professora Catherine Walsh (2009) aponta para a necessidade de pensar as políticas públicas dos anos 1990, o neoliberalismo e o crescimento de um discurso multicultural, numa perspectiva de acomodação da crítica. $\mathrm{Na}$ angariação de lutas sociais para dentro das instituições, ou dentro do discurso do sistema, numa espécie de acomodação da crítica desses grupos ao sistema. As categorias apresentadas pela autora nos ajudam a pensar nosso país. A explicação dos conceitos desenvolvidos ficou dessa maneira: Interculturalismo funcional $=$ responde e é parte dos interesses e necessidades das instituições sociais; e a interculturalidade crítica é uma construção de e a partir das pessoas que sofreram uma histórica submissão e subalternização.

As duas formas de interpretação sobre o conceito de interculturalidade nos ajudam a compreender a dinâmica operada pelos gestores públicos no âmbito de várias instituições do Estado, incluindo a escola, a história e os currículos.

A autora traz um debate sobre os limites da democracia apresentada aos segmentos subalternos e aponta para rupturas dos mesmos e a reivindicação por outros espaços que possam garantir a legitimidade de suas lutas e que operem transformações de fato, ou seja, a interculturalidade crítica como prática política.

Analisar as possibilidades decoloniais no ensino de história no atual currículo Paulista é construir embates com o movimento negacionista e o revisionismo histórico em curso. É também entender a ação de importantes grupos do setor financeiro dentro da elaboração do material didático, corroborando para uma versão bem mais enxuta dos conteúdos pertinentes a área de história e das ciências humanas em geral. 
A marca que diferencia e aprofunda uma mudança no Programa São Paulo Faz Escola implantado em 2008, da nova versão de 2019, é o projeto INOVA, publicado no dia 06/05/2019.

O Governador João Doria e o Secretário de Estado da Educação, Rossieli Soares, lançaram nesta segunda-feira (6) o "Inova Educação". O programa prevê novas atividades aos estudantes do $6^{\circ}$ ao $9^{\circ}$ ano do Ensino Fundamental e Ensino Médio do Estado de São Paulo, com ofertas de disciplinas eletivas e uso de novas ferramentas. (06/05/2019. Portal do Governo de SP).

$\mathrm{Na}$ prática, o projeto Inova Educação oferece uma adequação aos eixos centrais da BNCC, qual seja a reestruturação curricular e a inserção de novas disciplinas, são elas: Projeto de Vida, Tecnologias e as Eletivas. Recuperando a análise de Catherine Wash, aparentemente parece ser uma sintonia com as demandas do tempo presente, um acolhimento aos anseios da juventude. No entanto, ao olhar mais atentamente, é possível observar uma ingerência nas práticas pedagógicas e a ruptura da autonomia docente, acarretando um visível distanciamento da agenda antirracista e da preocupação da construção de um ensino de história decolonial ${ }^{3}$.

\section{Perspectivas de decolonialidade no ensino de História: escuta e leitura de Negros}

Recuperando a leitura de Fanon, Catherine aponta que, a descolonização é uma forma de (des)aprendizagem, de desaprender tudo que foi imposto e assumido pela colonização e desumanização para aprender a serem homens e mulheres. (WALSH,2009, p.35).

\footnotetext{
${ }^{3}$ Uma análise simples é verificarmos na nova disciplina do Projeto de Vida, os elaboradores temáticos da disciplina, no qual além dos servidores da SEDUC/EFAPE, é possível ver nome de outros agentes, como: o Instituto Airton Senna, Instituto de Corresponsabilidade pela Educação, Instituto Proaj. Na organização da disciplina de Tecnologia e Inovação, além dos sujeitos ligados ao campo educacional, é possível ler os nomes da Fundação Vanzolini, Fundação telefônica Vivo. Enfim, a inserção dessas novas disciplinas promovem uma reestruturação das unidades escolares. Nesta perspectiva, o debate decolonial, a retomada de análises relacionadas a história do Brasil e a construção de uma agenda antirracista acaba sendo quando muito mencionada, para cumprir o rito. O que começa a prevalecer é a perspectiva de construir processos educativos voltados para formação de sujeitos gestores de capital, os tais empreendedores. Esse é o INOV A Educação.
} 
O modelo de escola e os modelos de avaliação são mais dos alguns desafios para a educação escolar. Muito se tem discutido sobre a rigidez das matrizes curriculares, o empobrecimento do caráter conteudista dos currículos, a necessidade de diálogo entre escola, currículo e realidade social, a necessidade de formar professores e professoras reflexivos e sobre as culturas negadas e silenciadas nos currículos. Sobretudo as culturas indígenas e africanas ou afro-brasileiras. (Gomes, 2012, p104.)

Corroborando o observado por Nilma Lino Gomes (2012, p. 100), as artes têm reconhecido a centralidade das tensas relações étnico-raciais que acompanham a nossa formação social e cultural. Nesta perspectiva, apresento algumas práticas oriundas do processo de autonomia pedagógica comprometida com a decolonialidade, algumas possibilidades que desenvolvemos com os alunos, trabalhando os saberes negros.

Temática trabalhada: $\mathrm{O}$ processo abolicionista e as leis que o antecederam. A abolição da escravidão no Brasil. Atividade para os $8^{\circ}$ s e $9^{\circ}$ s anos, História do Brasil Pré-republicano, século XIX.

O mestre de capoeira Toni Vargas elaborou uma música de capoeira que traz questionamentos sobre a escrita e transmissão da história contada nas escolas brasileiras sobre o processo abolicionista, denunciando as opressões e os heróis construídos em torno do processo de abolição da escravidão, como a figura da princesa Isabel. A letra anuncia as ausências da trajetória das lutas de resistência negra, como uma reivindicação da luta quilombola, do olhar sobre as condições de moradia no pós-abolição entre outros temas, temas ausentes nas escolas. Lutas fundamentais que promoveram e tensionaram questionamentos antes e depois da assinatura da Lei Áurea.

O trabalho com a escuta e análise da letra da música foi posterior à apresentação das leis. A princípio discutimos a lei Eusébio de Queirós (1850), a Lei do Ventre Livre (1871) e a Lei dos Sexagenários (1885). O conjunto de leis foi resultado da movimentação dos abolicionistas. Por fim, a Lei Áurea (1888).

A música começa com o código penal da $1^{a}$ República, documento interessante, que nos mostra como a materialidade da ação estatal agiu para não agregar ao projeto de República os cidadãos negros.

\section{Código Penal da República dos Estados Unidos Do Brasil}

Decreto número 847

De 11 de outubro de 1890

Capítulo 13 
Dos vadios e capoeiras

Artigo 402

Fazer nas ruas e praças públicas

Exercícios de agilidade e destreza corporal

Conhecido pela denominação "Capoeiragem"

Andar em correrias com armas e instrumentos

Capazes de produzir lesão corporal

Provocando Tumulto ou desordem

Ameaçando pessoa certa ou incerta

Ou incutindo temor de algum mal

Pena: De Prisão celular de 2 à 6 meses

\section{Parágrafo único}

É Considerável circunstância agravante

Pertencer o capoeira a algum bando ou malta

Aos chefes ou cabeças

Se aplicará pena em dobro

Analisar a redação do código penal de 1892 é constatar o já denunciado por Frantz Fanon em "Os Condenados da Terra": "a violência colonial não tem somente o objetivo de garantir o respeito desses homens subjugados, procura desumanizá-los. Nada deve ser poupado para liquidar as suas tradições, para substituir a língua deles pela nossa, para destruir a sua cultura". (2018, p.54).

O neocolonialismo como política de estado no Brasil, mesmo com a recente instalada $1^{a}$ República, atualizou legalmente o racismo que estrutura a sociedade. E neste sentido, o código penal expressou como as culturas de matrizes africanas foram tratadas. Capoeira, samba, jongo, o candomblé, entre outras, tiveram suas manifestações e práticas criminalizadas, atribuindo aos praticantes o pejorativo de vadios ou feiticeiros.

Iêê

Dona Isabel que história é essa?

Dona Isabel que história é essa

Oi ai ai!

de ter feito abolição? 
De ser princesa boazinha que libertou a escravidão

Abolição se fez com sangue

Que inundava este país

Que o negro transformou em luta

Cansado de ser infeliz

Abolição se fez bem antes

E ainda há por se fazer agora

Com a verdade da favela

E não com a mentira da escola

O mestre Toni Vargas nas primeiras estrofes da música retoma os questionamentos das ausências e alerta sobre a necessidade de recontar a história de luta negra. História marcada por resistência e significativas contribuições do saber negro.

Dona Isabel chegou a hora!

De se acabar com essa maldade

De se ensinar aos nossos filhos

$\mathrm{O}$ quanto custa a liberdade

Viva Zumbi nosso rei negro

Que fez-se herói lá em Palmares

Viva a cultura desse povo

A liberdade verdadeira

Que já corria nos Quilombos

E já jogava capoeira

Iê! Viva Zumbi

(Iêê Viva Zumbi, Camará)

Iê! Rei de Palmares

(Iêê Rei de Palmares, Camará)

Iê! Libertador

(Iêê Libertador, Camará)

Iê! Viva Meu Mestre

(Iêê Viva Meu Mestre, Camará)

Iê! Quem me ensinou

(Iêê quem me ensinou, camará) 
Iê! A Capoeira

(Iêê a Capoeira, Camará)

Composição: Mestre Toni Vargas

Analisar o processo abolicionista e as leis que foram desenvolvidas no contexto anterior à assinatura da Lei Áurea, além de propor uma interação e análise da história a partir dos questionamentos apontados pelo mestre Toni Vargas, torna-se uma possibilidade de decolonialidade, pois permite trabalhar com uma cultura que foi considerada criminosa por ter sido criada por negros na condição de escravizados, objetificados, grupos subalternizados, destituídos de humanidade e marcados pela cor da pele.

É uma leitura de mundo, uma visão a partir do sujeito que é adepto dessa cultura. Uma crítica, uma inquietação provocada por narrativas hegemônicas compostas por heróis, governantes e elites.

A letra ainda aponta para os profissionais da História, a perspectiva de discutir outros personagens e conceitos: Zumbi, o conceito de quilombo, os conteúdos da História do Brasil sob a perspectiva das camadas inferiorizadas.

É possível colocar em discussão com os alunos como a História do Brasil Império está contada no currículo do Estado. Há espaço para críticas, debates e construção de caminhos? Trazemos os elementos abordados na música.

O código penal da $1^{a}$ República nos traz outras indagações: Que República foi essa? Como se ergueu? Quais os grupos e culturas foram excluídos ou favorecidos legalmente pelo Estado?

Interessante pensar a permanência das lutas quilombolas, a necessidade de avançarmos no debate sobre a questão da terra, da moradia no Brasil. Questões de ontem e hoje. Trabalhar um dos segmentos da cultura negra, a capoeira; prática cultural que tem uma história de resistência negra que foi criminalizada. Sua liberação como prática não criminosa veio somente com outro projeto de país nos anos de 1937, com o presidente Getúlio Vargas, para ser utilizada na construção de um projeto de identidade nacional.

Pautar a luta negra por visibilidade de corpos, por direitos, por reconhecimento da produção de saberes e fazeres nos currículos de História que desenvolvemos na sala de aula é propor ações decoloniais.

É lembrar que se trata de uma cultura de resistência, que atravessou séculos e, devido ao trabalho de homens e mulheres anônimos na sociedade brasileira, distribuiu essa cultura mundo afora. A capoeira foi reconhecida como 
Patrimônio Imaterial Brasileiro em 2008 e em 2014 a Organização das Nações Unidas para a Educação, Ciência e Cultura (UNESCO) declara a roda de capoeira como Patrimônio Imaterial da Humanidade.

Ao mesmo tempo, pautar a luta negra em sala de aula é enfrentar as tensões que estão estabelecidas no contexto histórico. Pensar a questão curricular do São Paulo Faz Escola, é pensar na redução da centralidade dos temas tão caros ao processo de descolonização do currículo e aos documentos produzidos ao longo da história da educação como os Parâmetros Curriculares e as leis antirracistas que foram construídas ao longo da primeira década do século XXI (10.639/03 e 11.645/08). O atual currículo está fortemente marcado pela contemplação das provas estandartizadas, pelos apostilados introduzidos na rede paulista desde o ano de 2008 e pela atual BNCC. No campo da História, operou um reducionismo de abordagem nas questões voltadas para a história do negro e do indígena no Brasil.

Entendemos que a prática decolonial corre o risco de ficar limitada ao diálogo entre acadêmicos e fugir da dimensão política, do enraizamento nas lutas de resistência das populações afrodiaspóricas, indígenas ou das camadas populares, e mesmo sem citar autores negros (MALDONADO-TORRES;GROSFOGUEL;COSTA,2020p.10). A outra atividade desenvolvida na perspectiva decolonial, realizada na escola pública Maria Aparecida Rodrigues, foi um debate entre o Brasil dos anos de 1950 e a obra de Carolina Maria de Jesus.

\section{Descolonizando na sala de aula: Experiência do ensino de história a partir do livro Quarto de Despejo de Caroli- na Maria de Jesus}

Ao refletir sobre o trabalho com a questão racial nos espaços escolares, descrevo o desenvolvimento de uma atividade de pesquisa com alunos do $1^{\circ}$ ano do Ensino Médio, realizada no ano de 2014, na Escola Estadual Maria Aparecida Rodrigues, periferia de Guarulhos, no ano de centenário de nascimento da autora, com o objetivo apresentar aos alunos a escrita das mulheres negras no espaço do conhecimento.

A atividade pedagógica foi a leitura da obra: Quarto de Despejo: Diário de uma favelada, o livro mais conhecido da escritora Carolina Maria de Jesus, texto que traz uma denúncia social extremamente forte para o contexto da época, escrito entre 1955 e 1958.

O texto de Carolina Maria de Jesus Quarto de Despejo, está localizado no 
conceito que a escritora Conceição Evaristo (2013), definiu como "Escre(vivência)", justificando a especificidade de entender a literatura na voz de mulheres negras. O livro apresenta a fome, descreve as condições de vida e moradia da primeira comunidade de favela, localizada no Canindé, em São Paulo, a partir de vários diários, escritos pela então catadora de papel, Carolina Maria de Jesus.

Entre sua cidade natal, Sacramento, e a São Paulo dos "anos dourados", Carolina viveu e escreveu em forma de diário muito do que se passava nos primeiros aglomerados de favelas em São Paulo. A voz de dentro da favela, de uma mulher negra, mãe de três filhos, catadora de papel e escritora. Segundo a pesquisadora Germana Sousa, "a especificidade de seu texto tem a ver com a sua escrita da vida de próprio punho, sem mediação. É uma escrita que se autorrepresenta como mulher, negra e pobre. Mas poeta.” (2012,p.33).

O historiador José Carlos Sebe localiza Carolina como uma escritora que:

\begin{abstract}
Despontou no cenário nacional nas agitações políticas que marcaram os chamados 'anos dourados', iniciados no governo de JK. No quadro da contracultura, cabiam tipos sociais que representassem as contradições nacionais. Nesse conjunto, a experiência de mulher batalhadora que sobrevivia graças ao lixo da cidade valia como argumento de interesse social. Foi assim que Carolina se transformou em representante de temas que empolgavam o debate político da esquerda e da direita. (1998, p.82).
\end{abstract}

A vida dessa personagem começou a mudar a partir de uma reportagem realizada pelo jornalista Audálio Dantas, no ano de 1958, na favela do Canindé. Ele conheceu os manuscritos de Carolina e começou a publicar artigos na "Folha da Noite", jornal em que trabalhava.

No ano 1960 foi publicada a primeira edição do livro Quarto de Despejo, um sucesso de vendas e conseguiu alcançar a marca de 80 mil cópias vendidas. Esse feito estabelece uma virada na vida da autora que compra sua casa em um bairro de classe média em Santana.

No início de 1960 o país estava vivendo um processo democrático. Os movimentos sociais começavam a ganhar mais espaço, surgia o movimento feminista, dava-se o crescimento urbano, o êxodo rural e o surgimento da televisão como meio de comunicação de massa, fatores que vão contribuir para a as censão repentina da escritora Carolina Maria de Jesus.

O texto é a escrita, testemunho de alguém que estava disposta a denunciar a condição de pobreza em que vivia, o cotidiano dos moradores da favela 
do Canindé, a separação geográfica entre ricos e pobres, a discriminação social, o machismo que presenciava no dia a dia de suas vizinhas, a amarela fome e o processo de favelização que então começava em São Paulo. Os relatos incluem a política. Em 1958 fala-se sobretudo do prefeito de São Paulo, Ademar de Barros, e do Presidente Juscelino Kubistchek.

Além dos aspectos citados, havia poesia em sua escrita e passagens lindas sobre a vida. Entre as anotações de seu diário de 15 de maio de 1958, está escrito: "Eu classifico São Paulo assim: O Palácio é a sala de visita. A Prefeitura é a sala de jantar e a Cidade é o jardim. E a favela é o quintal onde jogam os lixos" (JESUS, 2007, p.32). A crítica social mistura-se ao lirismo: "A noite está tépida. O céu já está salpicado de estrelas. Eu que sou exótica gostaria de recortar um pedaço do céu para fazer um vestido". (JESUS, 2007, p.32).

Trabalhar com os textos de Carolina é dialogar com a potência da escritora negra que sem nenhum glamour denunciava que a favela não é moradia digna de nenhum ser humano. É trabalhar uma personagem que nos anos de 1950, morando na comunidade, lutava bravamente para educar seus filhos, num contexto em que a educação era extremamente seletiva. É também denunciar a dimensão da estrutura racista do país em relação aos escritos negros, pois atualmente o livro Quarto de Despejo: diário de uma favelada, está traduzido em 17 línguas, reconhecido em mais de quarenta e cinco países e com mais de um milhão de exemplares vendidos em todo o mundo, e a provocação lançada aos alunos foi: por que permanece tão desconhecido dos brasileiros, principalmente dos que frequentam a escola pública neste país?

\section{A Recepção de Quarto de Despejo}

Envolvidos com a pesquisa sobre a vida de Carolina e seu centenário, a ideia de apresentar essa escrita foi buscar entender como os alunos receberiam a obra, que análise do cotidiano da autora fariam e qual sua importância para a escola pública.

As manifestações foram as mais variadas, porém em sua grande maioria o texto começou a empolgar pelo relato do cotidiano, não muito diferente do vivido pelos alunos, moradores da periferia de Guarulhos.

O diálogo com o texto de Carolina mostrou-se imediato, e tanto nos textos, quanto na exposição da pesquisa, os alunos falaram da importância da divulgação da obra.

Textos estes que apresentam desde uma leitura pessoal no sentido mais 
restrito da palavra ${ }^{4}$, até a necessidade de que as obras produzidas por Carolina se tornassem conhecidas pelo conjunto dos alunos das escolas públicas do país.

A aluna Rosana ${ }^{5}$, de 16 anos, escreveu sobre, apontando situações de semelhança com seu espaço social e indagando sobre o silêncio em relação à autora. $\mathrm{O}$ texto da aluna para um aspecto de empoderamento feminino:

A principal obra de Carolina Maria de Jesus, Quarto de Despejo, possui grande importância para a sociedade, principalmente para a escola pública.

Todos sabemos a situação das escolas públicas brasileiras e as dificuldades que tanto alunos como professores e funcionários enfrentam no cotidiano.. O descaso com a estrutura, segurança e superlotação de salas são os maiores problemas enfrentados por nós. Neste diário, ela relata exatamente a realidade dos moradores dos subúrbios

Ao serem apontados todos os problemas sociais de um local em crescimento, como ela fez, conseguimos encontrar suas causas. Em uma realidade não muito diferente da sua enfrentamos problemas de saneamento, moradia, violência, fome e preconceito. Todos batalham para conseguir alimento.

Podemos observar que o governo é movido só por interesse desde aquela época. A história de vida dessa mulher nos ensina a batalhar tanto para sobreviver como para fazer a diferença na sociedade que vivemos, que devemos mudar a situação que estamos no presente, quebrar as fronteiras que colocaram para separar aqueles que possuem dinheiro daqueles como nós, que vivem em periferia

O estudo da vida e obra de Carolina Maria de Jesus nos ensina e que se ainda estivesse viva e completando cem anos, ainda estaria em busca de seus direitos. Escrevendo não por dinheiro, mas pelo progresso daqueles que possuem necessidades não atendidas, como ela própria. $(08 / 05 / 2014)$

A aluna Ariany de 16 anos identificou-se com as palavras de Carolina e se arriscou a entender o esquecimento sobre a obra, e o tom crítico das denúncias sociais que a escritora fez durante o texto:

A Importância de Carolina Maria de Jesus é que ela serviu como espelho para nós jovens. Ela mostrou que não importa de onde viemos o impor-

\footnotetext{
${ }^{4}$ Os textos produzidos pelos alunos serão mantidos em sua grafia original, sem nenhuma intervenção, mostrando como cada aluno na sua singularidade, inclusive da escrita, expressou a leitura da obra de Carolina.

${ }^{5}$ Utilizaremos nomes fictícios afim de preservar a identidade dos alunos.
} 
tante é você querer, como pode uma catadora de papelão que mora em uma comunidade ser tão reconhecida se tornando uma das maiores escritoras.

Algumas pessoas tentam apagar ela da história fazendo seu nome sumir, mas isso porque ela queria mudar a sociedade. Ela relatava como que é morar em uma favela e criticava os políticos, essas pessoas que veem a desigualdade e mesmo assim, fazem cada dia mais o pobre ficar mais pobre e o rico ficar mais rico.

A importância dela é que nos mostrou que podemos mudar a sociedade, mudar o fato de que quem está em favelas não tem capacidade, ela mos trou o contrário, mostrou que se tivermos interesse em ter conhecimento e querer ser diferentes podemos. (08/05/2014).

Os dramas da mulher, mãe solteira, chefe de família, não foram incorporados ao acervo dos argumentos das feministas, escritoras ou não. Curiosamente, o testemunho daquela mulher que revelou com tanta intimidade suas agruras fica descartado do montante crítico das brasileiras que, de modo geral, insistem em garantir crédito às experiências estrangeiras em vez de olhar para o (nosso) próprio lado. Por certo essas observações devem induzir a uma conclusão impertinente que sugere que o feminismo brasileiro ainda está preso à clas se social das mulheres brancas e bem-postas na vida que preferem se mirar em espelhos alheios desde que estes reflitam status. Nesse sentido explicar-se-ia o "esquecimento" das negras (MEIHY, 1998, p. 90).

A aluna Cleonice de 16 anos, analisa a pesquisa sobre Carolina como uma possibilidade de pensar o seu espaço social e sua atuação como estudante: "O diário me fez pensar melhor na vida, para não pensar em largar os estudos e lá na frente ter uma faculdade boa e uma condição financeira melhor" (08/05/2014).

O aluno Amadeu de 16 anos, destaca a necessidade do espaço escolar conhecer Carolina Maria de Jesus e a mídia divulgar a importância da autora:

Carolina Maria de Jesus foi uma grande mulher para a sociedade brasileira. Após ter feito a pesquisa sobre essa autora, fiquei muito impressionado pela história de vida dela que não é muito diferente da nossa e pelo fato de ela ser uma catadora de recicláveis, ninguém prestou atenção, mas ela lutou e venceu na vida. Com apenas dois anos de estudos fez muitas obras fantásticas.

Carolina Maria em seus livros que escrevia com cadernos que achava durante o trabalho, fala sobre a migração dela para a cidade e a luta para sobrevivência em busca de sair da miséria. $\mathrm{Na}$ minha opinião, as emissoras 
de televisão deveriam homenagear uma mulher que não só foi, como é importantíssima para nossa sociedade. Todas as escolas deveriam ter algo sobre ela, pois poderia mudar o pensamento do aluno e conscientizar as pessoas de lutar por uma vida melhor e não se contentar com o pouco. (08/05/2014).

O texto de Luís Fernando, descreve a trajetória de vida da autora, sua infância pobre e sua pouca escolaridade, e finaliza mostrando a importância da obra:

Para mim, Carolina nos ajudou escrevendo cada dia de sua vida, pois ela nos mostra a outra realidade que acontecia em São Paulo, já que a mídia não relata muito esses lugares, só quando alguém morre em tiroteio, e a autora, mostrou com suas palavras o que acontecia com a maioria das favelas, seja no Rio de Janeiro ou em São Paulo.

Carolina mostrou que não há diferença de raças que uma pessoa negra pode tentar mudar a realidade, pois ela superou preconceitos, dificuldades e se tornou uma grande escritora para nossa literatura. $(08 / 05 / 2014)$.

O relato segue carregado de identificação, primeiro com o lugar, a vida em bairro periférico, com a questão de violência e traz uma reflexão no sentido da etnia, uma vez que a autora é uma mulher negra e ele um aluno negro. Escreve sobre a necessidade de superar o preconceito racial, enaltecendo a escritora como uma grande personagem da nossa literatura. A questão da identidade étnica foi muito forte, não só pra esse adolescente, mas para o conjunto de alunos que viram na trajetória da escritora mulheres de sua própria família, tanto no aspecto étnico como na vida de mulher e mãe de três filhos e solteira.

$\mathrm{O}$ aluno, Alessandro, mostrou que a condição de vida da escritora tem uma relação muito parecida com a vida que ele e tantos outros moradores de periferia têm, e que o uso da caneta, da escrita e do intelecto tirou a escritora da miséria social da favela do Canindé:

Embora não tenha seu devido reconhecimento pela sociedade, a obra de Carolina Maria de Jesus teve e ainda tem uma grande influência na concepção do que o esforço pode fazer, pois mesmo sendo humilde e com pouca escolaridade, ela conseguiu ter conhecimento por seus feitos, inusitadamente não foi por causa de futebol nem por causa de seu rebolado, mas sim por seu intelecto, por ter escrito um livro que foi bem relevante em meio a outros livros de grandes escritores. 
Por esse feito da Carolina muitos alunos têm tomado sua história como exemplo, e um desses muitos alunos sou eu! Isso mesmo, após ter estudado a obra de Carolina Maria de Jesus Quarto de Despejo, percebi que o tema desse livro é a vida de pessoas normais e banais como eu e você, trata de periferias, comunidades, moradores. Retrata nitidamente nosso meio social e nossas condições nessa sociedade.

(08/05/2014).

O texto do Alessandro dialoga com um debate muito presente na atualidade. Quando ele faz a leitura que Carolina "conseguiu ter conhecimento por seus feitos, inusitadamente não foi por causa de futebol nem por causa de seu rebolado, mas sim por seu intelecto", ele, de uma certa forma, recupera um debate colocado por Lélia Gonzalez, quando observa a dupla opressão da mulher negra pra tornar-se sujeito na sociedade.

O combate ao racismo e sexismo é urgente. Burros de carga do sexo (de que as mulatas brasileiras são um modelo), expressão das relações patriarcais racistas. Desse modo, se constata como a superexploração socioeconômica se faz aliada à superexploração sexual das mulheres amefricanas.(GONZALEZ, 1984).

A aluna Beatriz começou a atividade atribuindo um título ao texto, no qual é possível entender a recepção que o texto causou. A atividade elaborada pela aluna mostra o caráter realista do texto de Carolina, além de questionar a realidade social à qual tanto autora quanto aluna, estão submetidas:

\section{A obra de Carolina Maria de Jesus influencia escolas a mover estu- dantes.}

Carolina Maria de Jesus foi uma escritora brasileira que relatou sua vida na favela. Este livro pode sim nos influenciar para que nós, povo de periferia, possamos mudar as condições em que vivemos...

Ela foi uma mulher de muita audácia e coragem de relatar fatos de sua vida, incluindo pessoas de poder sem medo das consequências. Muitos jovens de hoje não tem muito contato com a leitura, porém tem muitas coisas que aconteceram em sua vida que podem servir de influência para outras pessoas.

As escolas em geral, assim como as públicas, deveriam passar este conhecimento para os alunos ali presentes, para mostrar os valores da escrita do Brasil; que nosso país possui sim, ótimos escritores que ao invés de falar sobre ficção ou algo relativo, contam fatos reais e de grande impor- 
tância para nós jovens.

Bom, essa autora foi e faz parte de nossa história, este ano completou seus 100 anos, nunca vimos passando na TV algo sobre ela, pois para as pessoas da alta sociedade lhe causam medo de aparecer mais escritores baseados nesta autora, pedindo melhores condições de vida e mostrando que não vivemos em condições boas e assim eles teriam que mudar. (08/05/2014).

Gabriela, ao compor seu trabalho, revela a força do texto, aponta o estranhamento da escritora não ter uma boa visibilidade entre nós, e discorre sobre a questão étnica, por esse silenciamento social em torno da produção literária de Carolina.

Tudo que Carolina relatava envolvendo as favelas, a vida que aquelas pessoas têm algo que nunca é mostrado e que a autora mostrou. A vida dentro das periferias ainda não teve uma mudança significativa, a exclusão é muito grande, passados mais de 50 anos, outro fato é que a falta de conhecimento sobre essa obra até mesmo dentro da favela, o que é preocupante, pois para ocorrer mais mudanças é necessária a continuação dessa história.

Uma mulher forte, que teve a coragem de se expressar quando todos ficavam calados, que merece o devido reconhecimento, uma literatura conhecida por outros países, mas não por nós. $\mathrm{O}$ mais interessante sobre a obra é que são fatos reais, vividos por quem escreveu e não uma invenção.

Em relação ao preconceito que existiu sobre a autora foi grande, pois estamos no ano de 2014 o centenário de Carolina Maria de Jesus. Mas nas mídias ninguém fala sobre a autora, será por que ela era pobre, morava em favela, tinha pele negra?

Eu penso que sim, e se fosse uma mulher rica e de pele branca, jornais, revistas e a televisão iam estar falando sobre ela?

A importância daquele livro relata tudo que na verdade acontece não só no Brasil como no mundo e que o governo nada faz para que mude para que as pessoas possam ter uma qualidade de vida melhor. (08/05/14)

Problematizar discursos é essencial e transformador. Assim, questionar os discursos literários abre um leque de possibilidades de interpretação, com uma ótica para as condições de produção, o esquecimento, o apagamento, os efeitos de sentidos, as relações de força e para o interdiscurso que reflete na constituição, construção e na institucionalização do sujeito inscrito na História. 
(RIBEIRO; RÊGO, 2019, p.208)

A obra de Carolina Maria de Jesus voltou a ser analisada pela academia a partir dos anos noventa do século XX, momento em que temos um crescimento da chamada literatura periférica e do movimento feminino. A pesquisadora Elisângela Aparecida Lopes alerta para importância da denúncia social presente em seu diário:

A escrita da experiência vivenciada ou a literatura de testemunho de Carolina Maria de Jesus caracteriza-se não só pela descrição intimista, mas também por um forte tom de denúncia. Nesse sentido, conforme nos alerta Ricoeur, a literatura de testemunho configura-se enquanto "huella sentimental" (marca sentimental), mas também como "huella social" (marca social): lugar de fala, manifestação da alteridade.

Os constantes questionamentos político-sociais presentes no diário de Carolina, assim como as denúncias da discriminação social que sofria marcam a marginalização dentro da marginalização: Carolina era discriminada por ser pobre, negra, mulher, catadora de papel, mãe solteira e escritora. (LOPES,2018).

O balanço dessa autora mineira, mulher negra, catadora de papel e mãe de três filhos carrega uma história de vida que muito tem a ensinar aos alunos e a toda sociedade, considerado uma espécie de literatura testemunho, literatura periférica e tantos outros termos que a obra de Carolina suscitou.

O livro apresenta uma reflexão muito interessante da vida nas comunidades de favela, aspecto que só intensifica a contribuição da autora com o público das escolas oficiais brasileiras. A relação com a sociedade, as mazelas e o preconceito que ainda não foram enfrentados e debatidos e se fazem presentes todos os dias nas salas de aula e no meio social.

A maioria das escolas públicas no Brasil tem um elevado número de alunos e alunas negras, o trabalho pedagógico e os referenciais pedagógicos que são oferecidos ao público negro encontram-se distantes de dialogar com sua identidade e fortalecer a imagem de homens e mulheres negras que construíram a história e a cultura desse país.

Diante da situação apontada, cabe a cada educador a tarefa de refletir e se posicionar sobre esse quadro, inclusive enfrentando as demandas burocráticas tão presentes no dia a dia dos professores e intensificando a construção da escola como espaço de pertencimento do aluno.

A construção de uma pedagogia antirracista deve começar por nossa própria descolonização. Na coleção organizada por Djamila Ribeiro: Feminismos 
plurais, ela chama atenção para o fortalecimento de práticas antirracistas, a começar pela leitura de autores negros, pela prática de repensar nossa formação, "é pensar projetos, novos marcos civilizatórios, para que pensemos um novo modelo de sociedade e de ações pedagógicas efetivamente decoloniais" (2017, p.84.).

Os aspectos histórico, didático e étnico de apresentar Carolina Maria de Jesus aos alunos estiveram focados na perspectiva de "arrancar" um comprometimento com a questão negra no currículo e no cotidiano escolar, fortalecendo o menino e menina não negros, mas principalmente, a menina negra o aluno negro a se entender e a se identificar enquanto sujeitos dentro do espaço escolar; a escrever, refletir, falar de sua comunidade, escola e sociedade, enfim de suas reflexões sobre o saber e também de suas histórias de vida. Autora de um acervo com mais de 5000 mil escritos, a obra da escritora mineira, segundo José Carlos Sebe, segue original e desafiadora:

O legado da escritora negra, catadora de papel, mulher incompreendida no cenário crítico geral, convida a pensar que, além do que se conhece, existe muito mais a ser revelado. Carolina escreveu obsessivamente durante toda a vida. E mais que diários. Em 37 cadernos, perfazendo mais de cinco mil páginas - com microfilmes à disposição do público na Biblioteca Nacional e com um caderno na Coleção Guita Mindlin em São Paulo, abre-se a possibilidade para que se dimensione o conhecimento de uma obra original, única e capaz de iluminar novos caminhos para a consideração da literatura nacional. (MEIHY, 1998, p. 92).

A obra da escritora é vasta e tem muito a ser divulgado, o pouco que conhecemos como os textos: Quarto de Despejo, Diário de Bitita, entre outros, contribui para os alunos se identificarem dentro do processo de ensino aprendizagem, permite instigar o exercício da escrita e do debate de temas cotidianos que necessitam de questionamento e tomada de postura diante da sociedade e Carolina é uma das possibilidades de diversificação curricular e de ampliação do repertório cultural dos alunos.

A filósofa Djamila Ribeiro, (2017, p.16), analisa que uma das tarefas de construção de uma educação antirracista, deve ser a divulgação da produção intelectual de mulheres negras, colocando-as na condição de sujeitos e seres ativos que, historicamente, vem fazendo resistência e reexistências.

A educação antirracista desafia os formadores à "desnaturalizar" e "historicizar o currículo existente", segundo Rita de Cássia Prazeres Fragella, (2009, p.194-195) significa tomar distância da concepção de que há o mundo da cultu- 
ra apresentado pela escola, sendo assim dois mundos são separados, conectados pela via da seleção e transmissão, mas entender que quando se faz escola, se faz educação, se faz cultura.

A retomada do questionamento ao currículo, proposto pela teoria crítica é eixo central quando falamos em descolonizar currículo, afinal não é sobre a forma de ensinar, ou seja, a metodologia que segue muito importante, mas as principais perguntas estão localizadas na problemática de saber: quais conhecimentos são considerados válidos? Quem são os sujeitos representados no currículo e quais outros são narrados? Quais embates, enfrentamentos e diálogos possíveis? (FRAGELLA, 2009, p. 194). Decolonialidade em um sentido contrahegemônico, como possibilidade em tempos de destruição.

\section{Considerações Finais}

O compromisso com a formação dos professores na perspectiva antirracista carrega uma dupla responsabilidade: a necessidade de investimento em formação, materiais didáticos e o acompanhamento das práticas pedagógicas; lembrando que a construção de projetos educativos emancipatórios implica, ainda, em conflito, confronto, negociação e o questionamento das relações de poder e do saber.

Como nos ensina a professora Nilma Gomes (2012, p.107.), a superação da perspectiva eurocêntrica de conhecimento e do mundo torna-se um desafio para a escola, os educadores e as educadoras, o currículo e a formação do cente.

A atuação política pedagógica, crítica e dialógica é o caminho e o desafio que está aberto aos profissionais da educação, a partir da educação infantil, passando pela escola fundamental, o ensino médio e o superior.

O caminho a seguir após os avanços da lei 10.639/03, juntamente com a 11.645/08 é a construção de outras posturas pedagógicas que sejam capazes de repensar e reelaborar a visão eurocêntrica que os próprios professores possuem, pois em geral foram educados dentro dessa visão, sendo necessário uma desconstrução e o questionamento do saber instituído.

O professor Kabenguele Munanga entende a questão curricular de maneira muito direta: "a questão é simples, basta incluir os outros conhecimentos inviabilizados e, assim ter um currículo que contemple todas as raízes formadoras do Brasil, sem excluir as raízes ocidentais, indígenas e africanas". A perspectiva da qual também comungamos é a de construir um processo educativo 
emancipatório e crítico, desenvolvendo uma educação que possa alternar entre o caráter crítico, perpassando pela educação dos sentidos, do enxergar e sentir, apontando para uma pedagogia multicultural e antirracista (2013, p.29).

Descolonizar Currículo na perspectiva do combate ao racismo significa avançar para além do campo da razão, para resolvermos o problema da identidade o trabalho terá de ser mais profundo. É necessário, diz ele, atingir o nível do imaginário e das representações, pois é este nível, para além do nível da lógica e da razão, o responsável por introjetar crenças, estereótipos e valores que codificam atitudes (MUNANGA, 2005, p. 29).

A introdução da escrita negra de Carolina Maria de Jesus nas atividades pedagógicas de alunos da escola pública corrobora a construção da descolonização do currículo, potencializa a visibilidade das mulheres negras na história; amplia o repertório cultural dos alunos e possibilita a construção de práticas da identidade de um grande conjunto de alunos que são alijados do currículo tradicional, devido ao viés etnocêntrico e racista.

Nesta experiência, a produção escrita dos alunos revelou o silenciamento da escrita de Carolina, chamou atenção para a falta de valorização de sua literatura e de sua imagem. O silêncio politicamente construído precisa ser questionado. Nesta perspectiva, a educação, as escolas, o ensino de História são caminhos importantes para fomentar práticas antirracistas, são o locus privilegiado da ação e do agir comunicativo na perspectiva decolonial.

\section{Referências}

ABREU, Martha. DANTAS, Carolina Vianna. MATOS, Hebe. (Orgs). O

Negro no Brasil: Trajetória e lutas em dez aulas de história. Rio de Janeiro: Objetiva, 2012.

ALMEIDA, Silvio. O que é Racismo Estrutural. São Paulo: Sueli Carneiro; Pólen, 2019.

APPLE, Michael. Escolas democráticas. São Paulo: Cortez, 1997.

ARROYO, Miguel. Currículo, Território em disputa. Petrópolis: Vozes, 2013.

Brasil. Ministério da Educação. Secretaria de Educação fundamental.

Parâmetros Curriculares Nacionais. Ética e Pluralidade Cultural, 1998.

Diretrizes Curriculares Nacionais para a Educação das Relações Étnico-Raciais e para o Ensino de História e Cultura Afro-Brasileira e Africana. MEC. Brasília: 2004.

. Lei de Diretrizes e Bases da Educação Nacional nº394/1996. 
[s.n], 1996.

Lei 10639/03.

Lei 11.645/08.

CAVALLEIRO, Eliane. (Org.). Racismo e anti-racismo na educação:

repensando nossa escola. São Paulo: Selo Negro, 2001.

DAVIS, Angela. (Org). Frank Barat. A Liberdade é uma Luta Constante.

São Paulo: Boitempo, 2018.

FRAGELLA, Rita de Cássia Prazeres. Diálogos interculturais, currículo e educação: experiências e pesquisas antirracistas com crianças na educação básica. Rio de Janeiro: Quartet- FAPERJ, 2009.

FREIRE, Paulo. Pedagogia do oprimido. São Paulo: Paz e Terra, 2005.

GOMES, Nilma Lino. Relações Étnico-Raciais, educação e Descolonização

Dos Currículos. Currículo sem Fronteiras, Paraná, v.12, n.1, p. 98-109, Jan/Abr 2012.

GONZALEZ, Lélia. Racismo e Sexismo na Cultura Brasileira. In: Revista Ciências Sociais Hoje, Anpocs, 1984, p. 223-244.

JESUS, Maria Carolina de. Quarto de despejo: diário de uma favelada. São Paulo: Ed. Ática, 2007.

LOPES, Elisângela Aparecida. A importância da leitura e da escrita para Carolina Maria de Jesus: uma análise do seu Quarto de despejo. Disponível em: <http://www.letras.ufmg.br/literafro >. Acesso em: 20 ago. 2020.

MEIHY. José Carlos Sebe Bom. Carolina Maria de Jesus: Emblema do Silêncio. Revista U S P, São Paulo, v. 3 7, n. 82-91, mar./maio,1998.

MUNANGA, Kabenguele. Políticas Curriculares e Descolonização dos Currículos: A Lei 10.639/03 e os Desafios para a Formação de Professores. Revista Educação e Políticas em Debate, Uberlândia, v.2, n.1, p. 29, jan./jul.2013.

Origens africanas do Brasil Contemporânea: histórias, línguas, culturas e civilizações. São Paulo: Global, 2009.

PEREIRA, Amilcar Araújo. O Negro no Brasil: Trajetória e lutas em dez aulas de história. (Orgs) DANTAS. Carolina Vianna, MATOS. Hebe, ABREU. Martha. 1. ed. Rio de Janeiro: Objetiva, 2012.

QUIJANO, Aníbal. 2005. Colonialidade do poder, eurocentrismo e América Latina. In: LANDER, Edgardo (org.). A colonialidade do saber: eurocentrismo e ciências sociais: perspectivas latino-americanas. Buenos Aires: CLACSO, set. 2005: 107-130. (ColecciónSurSur). 
RIBEIRO, Djamila. O que é lugar de fala?. Belo Horizonte (MG):

Letramento: Justificando, 2017.

RIBEIRO, Nathalie de Jesus Maria; RÊGO, Safira Ravenne da Cunha (orgs) O "Silenciamento" da voz negra feminina: uma análise discursiva da obra de Maria Firmina dos Reis. Cadernos Cajuína, São Luís, v. 4, n. 1, 2019.

RUFINO, Luiz. Pedagogia das Encruzilhadas. Rio de Janeiro: Mórula Editorial,2019.

São Paulo (Estado) Secretaria da Educação. Currículo do Estado de São Paulo: Ciências Humanas e suas tecnologias / Secretaria da Educação; coordenação geral, Maria Inês Fini; coordenação de área, Paulo Miceli, 1. ed. atual. - São Paulo: SE, 2011.

2020.

. SP Faz Escola. Caderno do aluno. Ciência Humanas. Ensino Médio.

SILVA, Maria. Aparecida. (orgs). Ações Afirmativas em Educação:

Experiências Brasileiras. São Paulo: Ed. Summus, 2003.

SOUSA, Germana. Carolina Maria de Jesus: O estranho diário da escritora vira-lata. Vinhedo: Ed. Belo Horizonte, 2012.

TORRES, Nelson Madonado; GROSFOGUEL, Ramón; COSTA; Joaze

Bernardino.(Orgs). Introdução: Decolonialidade e pensamento afrodiaspórico.

In: Decolonialidade e pensamento afrodiaspórico. Belo Horizonte:

Autêntica, 2020. p.10. (Coleção Cultura Negra e Identidades).

VARGAS, MestreToni. Dona Isabel. In: Álbum: Liberdade. 2007.CD/ LP.17 faixas 43min 23). < https://www.ouvirmusica.com.br/mestre-toni-vargas/>. Acesso em: 10 out. 2020.

WALSH, Catherine. 2009. Interculturalidade, crítica e pedagogia decolonial: insurgir, reexistir e re-viver. In: CANDAU, Vera Maria (org.). Educação intercultural na América Latina: entre concepções, tensões e propostas. Rio de Janeiro: 7 Letras. 